\title{
Improved Adaptive Position Update for Geographic Directing in Mobile Ad Hoc Networks
}

\author{
S.Theivasigamani, D.Vimala, I.Mary Linda
}

\begin{abstract}
In geographic directing, the hubs should keep up cutting-edge places of their prompt neighbors. Periodic telecom of guide packages that contain the geographic region bearings of the center points may be another framework utilized by most geographic controlling shows to keep up neighbor positions. The standard coordinating plans demonstrate that incidental beaconing paying little personality to the center point adaptability and development structures in the framework are not engaging from both revive cost and guiding execution viewpoint. Since the Adaptive Position Update (APU) method for geographic directing, which vivaciously deals with the repeat of position revives in perspective on the movability movement of the center points and the sending plans in the framework. Generally in Mobile Ad Hoc Networks, in the event that sending center points have high flexibility, at that point it may have numerous chances to make close-by topology mixed up in nature. Thusly this new Improved Adaptive Position Update (IAPU) system for Geographic coordinating chiefly overhauls the APU with low movability based sending center point decision. This annihilations the association disillusionment of the entire framework in high adaptability controlling. Consequently the preliminary comes about embodies that the proposed methodology drastically upgrades the execution of the current APU.[1,2,3,4]
\end{abstract}

Keywords : Geographic Routing; Beacon overhead; Unknown Neighbors Ratio

\section{INTRODUCTION}

Geographic steering conventions are turning into an appealing decision for use in portable impromptu systems .The fundamental rule utilized as a part of these conventions includes choosing the following directing bounce from among a hub's neighbors, which is geologically nearest to the goal. Since the sending choice is construct altogether with respect to neighborhood learning, it hinders the need to make and position-based directing conventions are very adaptable and especially vigorous to $[9,10,11,12]$ visit changes in the system topology. In addition, since the decision of transmitting is created on the fly, each gateway reliably chooses the optimal next step in view of the most present topology. A few examinations, have demonstrated that these steering conventions offer critical execution enhancements over

\section{Revised Manuscript Received on July 22, 2019.}

S.Theivasigamani, Department of Computer Science and Engineering, Bharath Institute of Higher education and research, Chennai , IndiaEmail: dheiva94@gmail.com

D.Vimala, Department of Computer Science and Engineering, Bharath Institute of Higher education and research, Chennai , IndiaEmail: vimalamuthu3@gmail.com

I.Mary Linda, Department of Computer Science and Engineering, Bharath Institute of Higher education and research, Chennai , IndiaEmail: catchlin.18@gmail.com keep up courses for every goal. By ideals of these qualities,

topology-based directing conventions, for example, DSR and AODV.

The sending methodology utilized in the previously mentioned geographic steering conventions requires the accompanying data, For instance, the location of the last package target and the location of the neighboring hub. The earlier can be acquired by questioning an area administration, for example, the Grid Location System (GLS) or Quorum . To get the last mentioned, every hub trades its own area data got utilizing GPS or the limitation plans examined in with its neighboring hubs. This enables every hub to construct a nearby guide of the hubs inside its region, frequently alluded to as the neighborhood topology. In any case, in conditions where center points are compact or when center points much of the time turn every so often, the area topology only from time to time remains static. Consequently, it is fundamental that each center point conveys its revived zone information to most of its neighbors. These zone revive packs are ordinarily suggested as reference focuses. In most geographic coordinating shows for example IGF, GeRaF , GPSR , reference focuses are imparted irregularly to keep up an exact neighbor list at each center.[5,6,7,8]

The geographic navigation conventions beaconing method called the Adaptive Position Updates (APU) scheme. By adapting to the framework variants, this scheme disposes of the downsides of intermittent beaconing. APU fuses two principles to set the refresh method for the reference point. The main control, alluded as Mobility Prediction (MP), utilizes a straightforward portability forecast plan to evaluate when the area data communicate in the past reference point winds up noticeably off base. The following reference point is communicated just if the anticipated mistake in the area appraise is more noteworthy than a specific limit, therefore tuning the refresh recurrence to the dynamism innate in the hub's movement. The second lead, referred to as On-Demand Learning (ODL), aims at improving topology accuracy along the conveying hubs ' directional paths. ODL utilizes an on-request learning technique, whereby a hub communicates reference points when it catches the transmission of an information parcel from another neighbor in its region. This guarantees hubs associated with for-warding information parcels keep up a more cutting-edge perspective of the neighborhood topology. Despite what might be expected, hubs that are not in the region of the sending way are unaffected by this control and don't communicate reference points much of the time. $[13,14,15,16]$

The APU is predominantly used to count the reference point overhead and the neighborhood topology exactness. 
Two dimensions, obscure neighbor ratio and incorrect neighbor ratio measure the neighboring topology accuracy. The prior steps, however, do not know the amount of fresh neighbours a receiving center is quite the sending hub's radio range. Despite what might be expected, the last speaks to the percent-period of out of date neighbors that are in the neighbor rundown of a hub, however have effectively moved out of the hub's radio range. The systematic outcomes are approved by broad recreations with the end goal that it demonstrates APU can adjust to portability and activity stack well. For every unique case, APU produces less or comparable measure of reference point overhead as other beaconing plans yet accomplish enhanced implementation as far as bundle conveyance proportion, normal end-to-end postpone and vitality utilization. In the second arrangement of recreations, this work assesses the execution of APU under the thought of a few true impacts, for example, a sensible radio proliferation model and restriction mistakes. The fundamental explanation behind every one of these enhancements in APU is that reference points produced in APU are more thought along the steering ways. Therefore, in APU, the hubs situated in the hotspots, which are in charge of sending a large portion of the information activity in the system have a cutting-edge perspective of their nearby topology, along these lines bringing about enhanced execution.

\section{PROBLEM STATEMENT}

Position invigorates are over the top from various perspectives. Each up-date eats up center essentialness, remote exchange speed, and grows the risk of pack crash at the medium access control (MAC) layer. Group effects cause package mishap which in this way impacts the coordinating execution as a result of lessened accuracy in choosing the privilege adjacent topology (a lost reference point impart isn't retransmitted). A lost data pack gets retransmitted, anyway to the weakness of extended start to finish delay. Clearly, given the expense related with transmitting signals, it looks good to change the repeat of guide updates to the center point flexibility and the development conditions inside the framework, rather than using static periodic revive approach. For instance, if certain hubs are much of the time changing their portability qualities (speed and heading), it bodes well to habitually communicate their refreshed position. Notwithstanding, for hubs that don't display critical dynamism, intermittent telecom of signals is inefficient. Further, if just a little level of the hubs are engaged with sending bundles, it is repetitive for hubs which are situated far from the sending way to utilize intermittent beaconing on the grounds that these updates are not helpful for sending the present activity.

Major Drawbacks of the Existing Scheme

- Position Updates within the Communication range.

- Increased node Energy Consumption.

- Packet Collision.

- Decreased Routing Performance (Packet Loss).

- Increased End to End delay.

\section{IMPROVED ADAPTIVE POSITION UPDATE}

The proposed Improved Adaptive Position Update(IAPU) approach for geographic controlling, which effectively changes the repeat of position revives in perspective on the flexibility components of the centers and the sending plans in the framework. IAPU relies upon two clear principles, for instance, Nodes whose advancements are more diligently to envision revive their positions even more normally, and Nodes closer to sending ways invigorate their positions even more once in a while. The accompanying are the methodical procedure of the IAPU in which it bit by bit expands the execution of the current Adaptive Position Update for Geographic directing with low versatility based sending hub determination. This thus additionally beats the connection disappointment of the whole system in high versatility steering.

\section{A. Beacon Updation}

In this operation, each hub should refresh its location as much as necessary through the reference point package, either soon or short, the hubs location changes. Refreshing every last either low or high development refreshing, it will expendmore vitality, and got by somebody in general or expanding sums after some time. [17-22]

\section{B. Mobility Prediction}

Versatility Prediction utilizes a straightforward portability forecast plan to assess when the area data communicate in the past guide winds up noticeably mistaken. The following signal is communicated just if the anticipated mistake in the area evaluate is more noteworthy than a specific edge, in this way tuning the refresh recurrence to the dynamism intrinsic in the hub's movement. An occasional signal refresh arrangement can't fulfill both these prerequisites all the while, since a little refresh interim will be inefficient for moderate hubs, though a bigger refresh interim will prompt erroneous position data for the very portable hubs. In our arrangement, in the wake of getting a reference point invigorate from a center point I, every one of its neighbor's records center point is available position and speed and irregularly track center point is region using a clear conjecture plot in perspective on direct kinematics. In perspective on this position harsh the neighbors can check whether center I is still inside their transmission extend and revive their neighbor list properly. The purpose of the MP run is to send the accompanying aide revive from center I when the bungle between the foreseen territory in the neighbors of I and center point I's genuine region is more significant than a commendable edge.[23-28]

\section{On Demand Learning}

Refresh sending way's nearest neighbor position for successful directing execution. Improve topology accuracy along the steering paths between the transport hubs. ODL uses an on-demand learning scheme whereby a center communicates guidelines when it receives data from another neighbour in its region. This ensures hubs associated with sending information bundles keep up a more a la mode perspective of the neighborhood topology. 
ODL utilizes an on-request learning technique, whereby a hub communicates reference points when it catches the transmission of an information bundle from another neighbor in its region. This guarantees hubs associated with sending information parcels keep up a more up and coming perspective of the nearby topology. In actuality, hubs that are not in the region of the sending way are unaffected by this lead and don't communicate reference points as often as possible. [29-34]

\section{Improved $A P U$}

If receiving hubs are highly versatile in Mobile Ad-hoc Networks, there may be a lot of possibilities to render neighboring topology incorrect. We improve steering implementation more than APU to upgrade with poor versatility-based sending hub option. In the event that we take high versatility directing, connect disappointment will influence the Whole Network. Through along these lines, we can ready to send information without connect disappointment. The enhanced APU is that reference points produced in APU are more focused along the steering ways, while the guides in every single other plan are more scattered in the entire system. Subsequently, in changed APU, the hubs situated in the hotspots, which are in charge of sending a large portion of the information movement in the system have an a la mode perspective of their neighborhood topology.

\section{PERFORMANCE ANALYSIS AND RESULTS}

The efficiency of the suggested method was assessed in this chapter by using three parameters that are as briefly described below. This assessment demonstrates that the Improved Adaptive Position Update exceeds the current method.

\section{A. Average Energy Consumption}

Consumption Energy Consumption is used primarily to measure total energy consumption in the network. It depends mainly on the overhead of the beacon and the total number of transmitting data packets.

\section{B. Throughput}

Throughput is the measurement in a specified quantity of moment of the effective information or signal transmitted across the communication channel. In other words, it is indicated that over the complete simulation moment, the complete amount of packets supplied.

\section{Packet Delivery Ratio}

Packet Delivery Ratio is the percentage of data packets that the target node receives to those produced in the transmission channel by the origin node.

\section{CONCLUSION}

In this paper, the requirement for adjustment of reference point refresh arrangement occupied with geographic steering conventions to the hub portability elements and the activity stack have been enormously recognized. The proposed Improved Adaptive Position Update (IAPU) system amends these issues as it were. The IAPU Scheme takes after two totally unrelated principles. The Mobility Prediction lead very gauges the exactness of the area as opposed to utilizing intermittent beaconing. At that point On Demand Learning principle allows the hubs along the information sending way

to maintain an exact perspective of nearby topology by supplanting reference points as for information bundles that are snooped from new neighbors. Notwithstanding the above, it is demonstrated that the low versatility based sending hub choice utilized as a part of IAPU beats the connection disappointment of the entire system in high portability steering procedure of APU. The mimicked execution of the proposed conspire subsequently over energy consumption, throughput, and the packet delivery ratio measures flank conventional geographic guidance methodologies. Future work involves the possibility of connecting the proposed procedure to achieve the ideal radio range and heap adjustment while evaluating in the Mobile Ad Hoc Network with the TCP association.[35-40]

\section{REFERENCES}

[1] A., Rangarajan K.,Algorithm for automaton specification for exploring dynamic labyrinths, Indian Journal of Science and Technology,V-6,I-SUPPL5,PP-4554-4559,Y-2013

[2] P. Kavitha, S. Prabakaran "A Novel Hybrid Segmentation Method with Particle Swarm Optimization and Fuzzy C-Mean Based On Partitioning the Image for Detecting Lung Cancer" International Journal of Engineering and Advanced Technology (IJEAT) ISSN: 2249-8958, Volume-8 Issue-5, June 2019

[3] Kumaravel A., Meetei O.N.,An application of non-uniform cellular automata for efficient cryptography,2013 IEEE Conference on Information and Communication Technologies, ICT 2013,V-,I-,PP-1200-1205,Y-2013

[4] Kumarave A., Rangarajan K.,Routing alogrithm over semi-regular tessellations,2013 IEEE Conference on Information and Communication Technologies, ICT 2013,V-,I-,PP-1180-1184,Y-2013

[5] P. Kavitha, S. Prabakaran "Designing a Feature Vector for Statistical Texture Analysis of Brain Tumor" International Journal of Engineering and Advanced Technology (IJEAT) ISSN: 2249-8958, Volume-8 Issue-5, June 2019

[6] Dutta P., Kumaravel A.,A novel approach to trust based identification of leaders in social networks, Indian Journal of Science and Technology,V-9,I-10,PP--,Y-2016

[7] Kumaravel A., Dutta P.,Application of Pca for context selection for collaborative filtering,Middle - East Journal of Scientific Research,V-20,I-1,PP-88-93,Y-2014

[8] Kumaravel A., Rangarajan K.,Constructing an automaton for exploring dynamic labyrinths,2012 International Conference on Radar, Communication and Computing, ICRCC 2012,V-,I-,PP-161-165,Y-2012

[9] P. Kavitha, S. Prabakaran "Adaptive Bilateral Filter for Multi-Resolution in Brain Tumor Recognition” International Journal of Innovative Technology and Exploring Engineering (IJITEE) ISSN: 2278-3075, Volume-8 Issue-8 June, 2019

[10] Kumaravel A.,Comparison of two multi-classification approaches for detecting network attacks, World Applied Sciences Journal,V-27,I-11,PP-1461-1465,Y-2013

[11] Tariq J., Kumaravel A.,Construction of cellular automata over hexagonal and triangular tessellations for path planning of multi-robots,2016 IEEE International Conference on Computational Intelligence and Computing Research, ICCIC 2016,V-,I-,PP--,Y-2017

[12] Sudha M., Kumaravel A.,Analysis and measurement of wave guides using poisson method,Indonesian Journal of Electrical Engineering and Computer Science,V-8,I-2,PP-546-548,Y-2017

[13] Ayyappan G., Nalini C., Kumaravel A., Various approaches of knowledge transfer in academic social network,International Journal of Engineering and Technology,V-,I-,PP-2791-2794,Y-2017

[14] Kaliyamurthie, K.P., Sivaraman, K., Ramesh, S. Imposing patient data privacy in wireless medical sensor networks through homomorphic cryptosystems 2016, Journal of Chemical and Pharmaceutical Sciences 92. 
[15] Kaliyamurthie, K.P., Balasubramanian, P.C.An approach to multi secure to historical malformed documents using integer ripple transfiguration 2016 Journal of Chemical and Pharmaceutical Sciences 92 .

[16] A.Sangeetha,C.Nalini,"Semantic Ranking based on keywords extractions in the web", International Journal of Engineering \& Technology, 7 (2.6) (2018) 290-292

[17] S.V.GayathiriDevi,C.Nalini,N.Kumar,"An efficient software verification using multi-layered software verification tool "International Journal of Engineering \& Technology, 7(2.21)2018 454-457

[18] C.Nalini,ShwtambariKharabe,"A Comparative Study On Different Techniques Used For Finger - Vein Authentication", International Journal Of Pure And Applied Mathematics, Volume 116 No. 82017 , 327-333, Issn: 1314-3395

[19]M.S. Vivekanandan and Dr. C. Rajabhushanam, "Enabling Privacy Protection and Content Assurance in Geo-Social Networks", International Journal of Innovative Research in Management, Engineering and Technology, Vol 3, Issue 4, pp. 49-55, April 2018.

[20] Dr. C. Rajabhushanam, V. Karthik, and G. Vivek, "Elasticity in Cloud Computing", International Journal of Innovative Research in Management, Engineering and Technology, Vol 3, Issue 4, pp. 104-111, April 2018.

[21] K. Rangaswamy and Dr. C. Rajabhushanamc, "CCN-Based Congestion Control Mechanism In Dynamic Networks", International Journal of Innovative Research in Management, Engineering and Technology, Vol 3, Issue 4, pp. 117-119, April 2018.

[22] Kavitha, R., Nedunchelian, R., "Domain-specific Search engine optimization using healthcare ontology and a neural network backpropagation approach", 2017, Research Journal of Biotechnology, Special Issue 2:157-166

[23]Kavitha, G., Kavitha, R., "An analysis to improve throughput of high-power hubs in mobile ad hoc network" , 2016, Journal of Chemical and Pharmaceutical Sciences, Vol-9, Issue-2: 361-363

[24] Kavitha, G., Kavitha, R., "Dipping interference to supplement throughput in MANET", 2016, Journal of Chemical and Pharmaceutical Sciences, Vol-9, Issue-2: 357-360

[25] Michael, G., Chandrasekar, A.,"Leader election based malicious detection and response system in MANET using mechanism design approach", Journal of Chemical and Pharmaceutical Sciences(JCPS) Volume 9 Issue 2, April - June 2016.

[26] Michael, G., Chandrasekar, A.,"Modeling of detection of camouflaging worm using epidemic dynamic model and power spectral density", Journal of Chemical and Pharmaceutical Sciences(JCPS) Volume 9 Issue 2, April - June 2016.

[27] Pothumani, S., Sriram, M., Sridhar, J., Arul Selvan, G., Secure mobile agents communication on intranet,Journal of Chemical and Pharmaceutical Sciences, volume 9, Issue 3, Pg No S32-S35, 2016

[28] Pothumani, S., Sriram, M., Sridhar, Various schemes for database encryption-a survey, Journal of Chemical and Pharmaceutical Sciences, volume 9, Issue 3, Pg NoS103-S106, 2016

[29] Pothumani, S., Sriram, M., Sridhar, A novel economic framework for cloud and grid computing, Journal of Chemical and Pharmaceutical Sciences, volume 9, Issue 3, Pg No S29-S31, 2016

[30] Priya, N., Sridhar, J., Sriram, M. "Ecommerce Transaction Security Challenges and Prevention Methods- New Approach” 2016 ,Journal of Chemical and Pharmaceutical Sciences, JCPS Volume 9 Issue 3.page no:S66-S68

[31] Priya, N.,Sridhar,J.,Sriram, M."Vehicular cloud computing security issues and solutions" Journal of Chemical and Pharmaceutical Sciences(JCPS) Volume 9 Issue 2, April - June 2016

[32] Priya, N., Sridhar, J., Sriram, M. "Mobile large data storage security in cloud computing environment-a new approach" JCPS Volume 9 Issue 2. April - June 2016

[33] Anuradha.C, Khanna.V, "Improving network performance and security in WSN using decentralized hypothesis testing "Journal of Chemical and Pharmaceutical Sciences(JCPS) Volume 9 Issue 2, April - June 2016

[34] Anuradha.C, Khanna.V, "A novel gsm based control for e-devices" Journal of Chemical and Pharmaceutical Sciences(JCPS) Volume 9 Issue 2, April - June 2016 .

[35] Anuradha.C, Khanna.V, "Secured privacy preserving sharing and data integration in mobile web environments " Journal of Chemical and Pharmaceutical Sciences(JCPS) Volume 9 Issue 2, April - June 2016.
[36] Sundarraj, B., Kaliyamurthie, K.P. Social network analysis for decisive the ultimate classification from the ensemble to boost accuracy rates 2016 International Journal of Pharmacy and Technology 8

[37] Sundarraj, B., Kaliyamurthie, K.P. A content-based spam filtering approach victimisation artificial neural networks 2016 International Journal of Pharmacy and Technology $\quad 8 \quad 3$.

[38] Sundarraj, B., Kaliyamurthie, K.P. Remote sensing imaging for satellite image segmentation 2016 International Journal of Pharmacy and Technology 83.

[39] Sivaraman, K., Senthil, M. Intuitive driver proxy control using artificial intelligence 2016 International Journal of Pharmacy and Technology 84.

[40] Sivaraman, K., Kaliyamurthie, K.P. Cloud computing in mobile technology 2016 Journal of Chemical and Pharmaceutical Sciences 92.

[41] Sivaraman, K., Khanna, V. Implementation of an extension for browser to detect vulnerable elements on web pages and avoid click jacking 2016 Journal of Chemical and Pharmaceutical Sciences 9 2 .

\section{AUTHORS PROFILE}

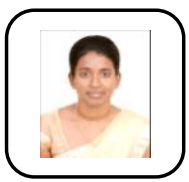

S.Theivasigamani, Assistant Professor, Department of Computer Science \& Engineering, Bharath Institute of Higher Education and Research, Chennai, India

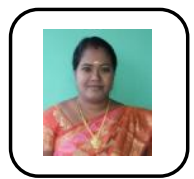

D.Vimala ,Assistant Professor, Department of Computer Science \& Engineering, Bharath Institute of Higher Education and Research, Chennai, India

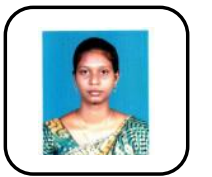

Mary Linda I, Assistant Professor, Department of Computer Science \& Engineering, Bharath Institute of Higher Education and Research, Chennai, India 